\title{
PERENCANAAN PEMASARAN \\ KERAJINAN BERBAHAN KAIN FLANNEL
}

Nofita Junian Triyana

1. Produk yang di jual : Kerajinan dari kain flanel

2. Harga jual produk

\begin{tabular}{|l|l|l|l|}
\hline Nama barang & Harga jual & Jumlah & Ketrangan \\
\hline Bros & Rp. 10.000 & 1 bungkus & Semua varian \\
\hline $\begin{array}{l}\text { Macam-macam bentuk } \\
\text { bunga }\end{array}$ & $\begin{array}{l}\text { Tergantung Bentuk } \\
\text { dan Ukuran }\end{array}$ & 1 bungkus & Semua varian \\
\hline Gantungan Kunci & Rp. 10.000 & 1 bungkus & Semua varian \\
\hline Bentuk-bentuk Lainnya & Mulai dari Rp. 10.000 & 1 Bungkus & \\
\hline
\end{tabular}

3. Bentuk promosi yang dilakukan : memberikan potongan harga bagi pelanggan untuk menarik minat beli pelanggan terhadap produk yang dijual

4. Bentuk pendistribusian yang dilakukan : COD bagi dalam kota dan di kirim bagi luar kota

Perencanaan pemasaran pengembangan produk yang akan dilakukan adalah melakukan inovasi dan lebih kreatif lagi untuk memenuhi produk yang diinginkan konsumen atau pelanggan. Dan akan memperluas barang yg akan diproduksi dari kain flanel tidak hanya bentuk bros saja seperti gantungan kunci,hiasan dinding,boneka,bunga dll

Penetapan harga untuk produk ini disesuaikaan dengan keinginan pelanggan. Pemasaran untuk produk ini adalah promosi melalu media sosial seperti facebook,ig dll dan targetnya adalah mulai dari remaja sampai ibu-ibu yang gemar main sosial media. Dan penjual melakukan perencanaan pemasaran menggunakan saluran distribusi menyediakan layanan pesan antar ke konsumen atau mengirim langsung sesuai dengan alamat pemesan.

Gambar ukm kerajinan dari kain flanel 

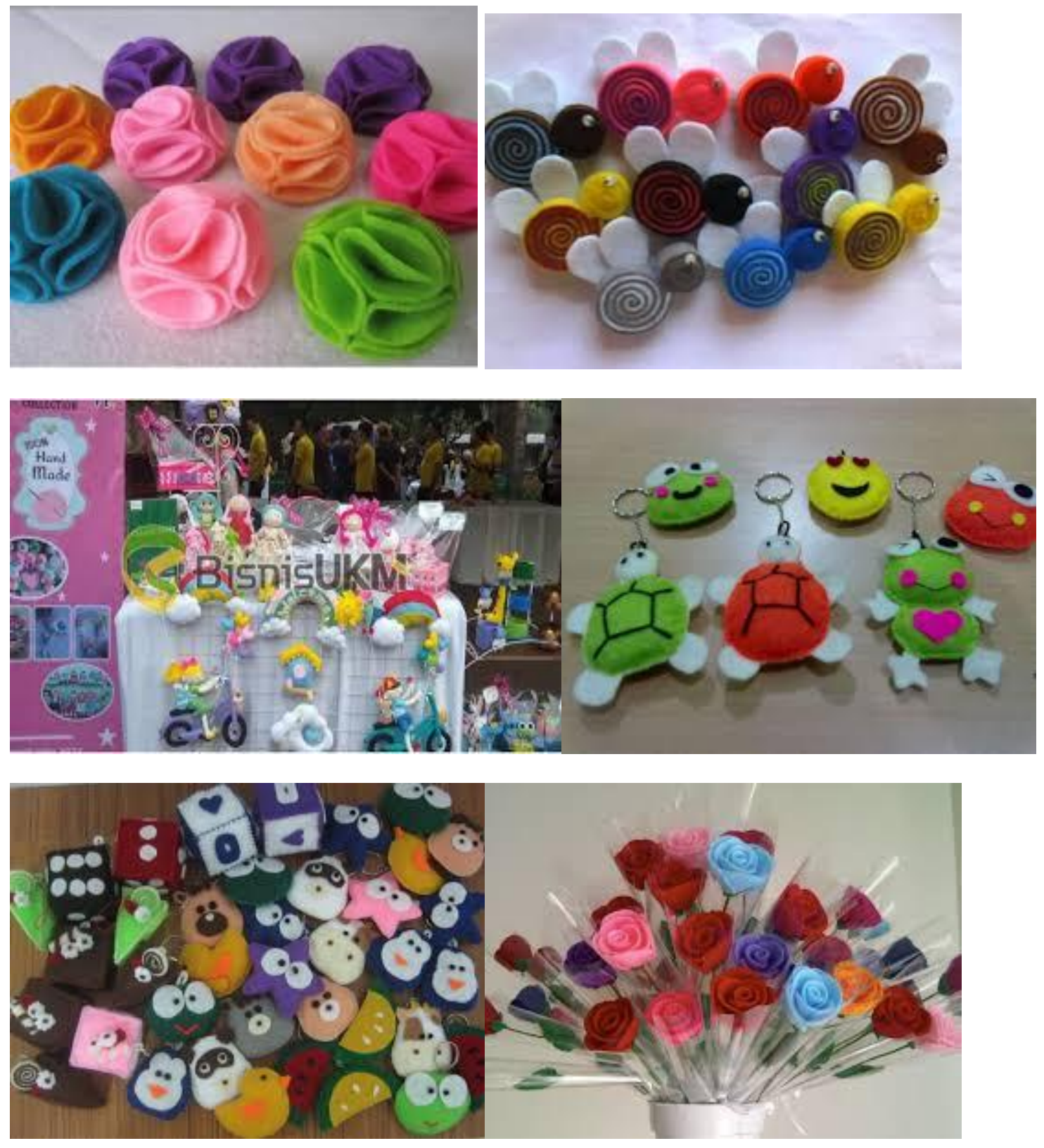

Referensi :

Mulyana, M., Hidayat, L., \& Puspitasari, R. (2019). Mengukur Pengetahuan Investasi Para Mahasiswa Untuk Pengembangan Galeri Investasi Perguruan Tinggi. JAS-PT (Jurnal Analisis Sistem Pendidikan Tinggi Indonesia), 3(1), 31-52.

Binangkitsari, L. (2018). The Influence of Brand Equity Elements on Purchase Decision and Its Imlication on Customer Loyalty.

Sulistiono, S., \& Bawono, S. (2009). Membangun Strategi Promosi Dalam Pengembangan Bisnis. Jurnal Ilmiah Kesatuan (JIK), 11(2).

Munawar, A., \& Purba, J. H. V. (2006). Kajian Dampak Pelatihan terhadap Kinerja Karyawan. Jurnal Ilmiah Kesatuan Nomor, 8(7), 2. 
Munawar, A., \& Marpaung, B. S. (2013). Pengaruh Arus Kas Operasi Terhadap Peningkatan Kemampulabaan dan Pertumbuhan Perusahaan. Jurnal Ilmiah Manajemen Kesatuan, 1(3).

Pamungkas, B., \& Mustikawati, D. S. (2015). Analisis Penerapan PSAK 45 (Revisi 2011) Terhadap Penyusunan Laporan Keuangan Entitas Nirlaba (Studi Kasus pada Yayasan Dharma Setia Kosgoro). Jurnal Ilmiah Akuntansi Kesatuan, 3(2), 101-110.

Fadillah, A., Sujana, S., \& Sukartaatmadja, I. (2019). Kajian Minat Studi Lanjut Siswa-Siswi SMA dan SMK Kota Bogor Ke Perguruan Tinggi. JAS-PT (Jurnal Analisis Sistem Pendidikan Tinggi Indonesia), 3(1), 53-62.

Pauziah, P., \& Mulyana, M. (2018). Formulation of The Green Marketing Development Strategy for the Body Shop Botani Square Bogor. In THE INTERNATIONAL CONFERENCE ON ACCOUNTING AND MANAGEMENT SCIENCE (p. 171).

Maulana, M. A., Iriyadi, I., \& Nurjanah, Y. (2018). Financial Reporting for Micro Small and Medium Enterprises Towards Industrial Revolution Era 4.0. In THE INTERNATIONAL CONFERENCE ON ACCOUNTING AND MANAGEMENT SCIENCE (p. 32-38). 